\title{
Fé, princípio-ativo, testemunhos de cura e rastreamento na produção de remédios caseiros por raizeiras e raizeiros do cerrado
}

Faith, active principle, testimonies of healing and tracking in the production of homemade remedies by raizeiras and raizeiros do cerrado

\section{Sabrina D'Almeida}

\section{(2) OpenEdition Journals}

\section{Edição electrónica}

URL: http://journals.openedition.org/aa/7682

DOI: $10.4000 /$ aa. 7682

ISSN: 2357-738X

\section{Editora}

Programa de Pós-Graduação em Antropologia Social (UnB)

\section{Edição impressa}

Paginação: 190-210

ISSN: 0102-4302

\section{Refêrencia eletrónica}

Sabrina D'Almeida, «Fé, princípio-ativo, testemunhos de cura e rastreamento na produção de remédios caseiros por raizeiras e raizeiros do cerrado», Anuário Antropológico [Online], v.46 n.1 | 2021, posto online no dia 03 janeiro 2021, consultado o 27 abril 2021. URL: http://journals.openedition.org/aa/ 7682 ; DOI: https://doi.org/10.4000/aa.7682

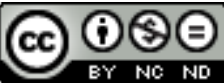

Anuário Antropológico is licensed under a Creative Commons Atribuição-Uso Não-Comercial-Proibição de realização de Obras Derivadas 4.0 International. 


\section{anuário antropológico}

$46 \cdot n \cdot 1 \cdot j a n e i r o-a b r i l \cdot 2021.1$

\section{Fé, princípio-ativo, testemunhos de cura e rastreamento na produção de remédios caseiros por raizeiras e raizeiros do cerrado}

Faith, active principle, testimonies of healing and tracking in the Production of homemade remedies by raizeiras and raizeiros do cerrado DOI: https://doi.org/10.4000/aa.7682

Sabrina D’Almeida • Universidade Federal Rural do Rio de Janeiro - Brasil

Professora substituta no Departamento de Ciências Sociais da Universidade Federal Rural do Rio de Janeiro (UFRRJ) e pesquisadora do Centro Brasileiro de Análise e Planejamento (CEBRAP).

A partir da descrição etnográfica do projeto de autorregulação do ofício de raizeiras e raizeiros reunidos em torno da Articulação Pacari, este artigo pretende problematizar sobre as supostas fronteiras entre religião, ciência e política. Trata-se de um projeto que incorporou para o ofício de raizeiras e raizeiros alguns elementos reconhecidos como científicos sem, contudo, abandonar outros repertórios que compõem suas trajetórias. 0 resultado destas dinâmicas produziu um conjunto original de práticas e saberes não previstos anteriormente e que desafia dicotomias clássicas - como a de tradição e modernidade - e que será objeto de análise deste artigo.

Raizeiras. Raizeiros. Medicina tradicional. Vigilância sanitária.
From the ethnographic description of the project for self-regulation of the craft of raizeiras and raizeiros gathered around the Articulação Pacari, this article aims to problematize the supposed boundaries between religion, science, and politics. It is a project that has incorporated for the craft of raizeiras and raizeiros some elements recognized as scientific without, however, abandoning other repertoires that make up their trajectories. The result of these dynamics has produced an original set of practices and knowledge not previously foreseen and that challenges classic dichotomies - such as that of tradition and modernity and that will be the object of analysis in this article.

Raizeiras. Raizeiros. Traditional medicine. Sanitary surveillance. 


\section{Introdução'}

Desde 2003, raizeiras e raizeiros do cerrado, reunidos em torno da Articulação Pacari, vêm desenvolvendo um projeto de autorregulação de seu ofício. Seus esforços no âmbito deste empreendimento encontram-se voltados à demonstração de que a fabricação de remédios caseiros não depende de práticas aleatórias, mas, ao contrário, são providas de fundamentos, lógica e regras, embora oriundas de outra tradição cultural e espiritual ${ }^{2}$. Conforme veremos, a reivindicação de autorregulação imprime um largo espectro de regras que passam a normatizar as condutas nesse campo popular e são orientadas, de acordo com uma de suas sócio-fundadoras, para garantir a segurança - tanto das raizeiras e raizeiros quanto dos remédios produzidos.

Tal projeto se mostra interessante do ponto de vista analítico, pois nos permite problematizar dois aspectos. De um lado, ele permite desconstruir a premissa, disseminada entre parte da classe biomédica e encontrada nos documentos da OMS sobre o tema ${ }^{3}$, de que a medicina tradicional/popular ${ }^{4}$ consistiria num conjunto de práticas e saberes engessados pelo tempo e pela tradição, associados às crenças culturais e, por isso mesmo, refratário às mudanças, inovações e intercâmbios com outros sistemas de cura. Veremos ainda que esta premissa é muitas vezes também compartilhada pelos próprios atores destas práticas como parte de um essencialismo estratégico.

De outro lado, o projeto demonstra que a prática de fabricação de remédios caseiros pelas raizeiras e raizeiros articulados se constitui como um misto de diferentes domínios e temporalidades, no qual religião e ciência, política, tradição e inovação se sobrepõem numa mesma ação, superando as dicotomias clássicas por meio das quais se costumou enquadrar as ações dos atores. Ou seja, por meio dele é possível demonstrar, por exemplo, como elementos provenientes do universo religioso se combinam com elementos do universo científico, recentemente incorporados por estas raizeiras e raizeiros.

Para compreender adequadamente suas práticas, é necessário se desprender temporariamente das oposições que ficam tão salientes nos discursos de agentes biomédicos, de órgãos nacionais e internacionais de saúde e, até mesmo, das próprias raizeiras e raizeiros que constroem seu ofício a partir de uma relação de oposição à medicina oficial. Observar tais práticas nos faz lembrar da improdutividade de as definirmos de antemão, para fins analíticos, ora como exclusivamente religiosas, ora políticas, ou científicas. Sem termos a pretensão de classificar suas atividades como científicas ou mágico-religiosas, tradicionais ou modernas, se estão inseridas no campo da ciência e da razão ou no da magia e religião, buscaremos, ao contrário, mostrar as interpenetrações e tensões que organizam estes campos que foram historicamente definidos como antagônicos, mas que a prática demonstra o quanto estão imbricados mutuamente.

Stanley Tambiah (1990) nos mostra como alguns ícones que abriram a era científica - caso dos precursores do iluminismo - se valiam de um arsenal de
1 Este artigo é resultado de pesquisa de doutorado realizada no Programa de Pós-Graduação em Antropologia Social da Universidade de São Paulo, com o apoio da Capes.

2 De acordo com o Protocolo Comunitário Biocultural das Raizeiras do Cerrado, elaborado pela Articulação Pacari, essas práticas estariam fundamentadas principalmente no conhecimento tradicional e na experiência das raizeiras, a partir de valores culturais e espirituais (2014, p. 18).

3 A esse respeito, ver Toniol (2012), Fleischer (2011) e D'Almeida (2018).

4 Práticas de benzimento, remédios elaborados a partir de plantas medicinais, pajelança cabocla, orações, entre outros, correspondem à variedade das expressões daquilo que foi tratado na literatura como uma medicina popular ou tradicional (OLIVEIRA, 1983; MAUÉS, 1994) e foram tomados como práticas "médicas", no sentido talvez metafórico do termo, uma vez que, apesar de sua ignorância relativa com relação às causalidades químico-biológicas das doenças, se propunham a descrever um conjunto mais ou menos definido de males, relacionados a uma forma particular de determinar suas causas e suas correlatas "medicinas". 
saberes e técnicas provenientes de domínios que à época eram associados à magia - como a alquimia e a astronomia - para formular suas teorias. Ao descrever essas dinâmicas, o autor procurou mostrar a superficialidade da separação entre magia e ciência, pois aquilo que era considerado magia na percepção religiosa do período é interpretado pelo autor como os primórdios das descobertas científicas da química e da astronomia.

A noção de "múltiplos ordenamentos de realidade" formulada por esse autor se mostra produtiva para compreendermos a prática de produção de remédios caseiros pelas raizeiras e raizeiros da Articulação Pacari. Conforme buscaremos demonstrar 5 , elas lidam com múltiplos ordenamentos de realidade no cotidiano de seu ofício: se preparam espiritualmente, "rezam a planta", rastreiam, observam critérios de segurança e qualidade e comprovam por meio de testemunhos de cura. Neste sentido, estas ações se mostram como formas igualmente importantes de interagirem com o mundo ao seu redor. Não se observa uma substituição de uma forma pela outra, uma vez que o fato de adotarem procedimentos reconhecidos como científicos, como veremos, não faz com que abandonem sua preparação espiritual. Para Tambiah (1990; 2013), os múltiplos ordenamentos de realidade estão simultaneamente disponíveis e podem ser acionados de forma contextual. Segundo o autor,

de acordo com a ocasião e o contexto, nós invocamos, empregamos e manipulamos corpus de idiomas e conceitos, culturalmente disponíveis e adaptados para se encaixar em diferentes sistemas de conhecimento, estilos de racionalidade e retórica, e modos de experiência emocional. Nesse sentido, nós somos flexíveis e plurais e nos engajamos em muitos modos de fazer-o-mundo. E apesar de sociedades e culturas de fato se diferenciarem umas das outras pela variedade de discursos que cada uma permite e incentiva, certamente não há notícia, até agora, de uma sociedade conhecida como praticamente inveterada de apenas uma das orientações (2013, p. 214).

\section{Repertórios articulados}

As abordagens que costumavam opor biomedicina e medicina popular por meio de categorias dicotômicas como tradicional e moderno, sagrado e profano, lógico e ilógico teriam sido superadas, de acordo com Canesqui (1994), já na década de 1980. Aos poucos teriam sido substituídas por análises nas quais os dois sistemas terapêuticos se encontram em relação de complementaridade e/ou subordinação num campo de relações de poder.

Dados os avanços nesse sentido, mostrou-se improdutivo tentar abarcar todo um complexo de práticas e saberes terapêuticos por meio de duas categorias dicotômicas, concebendo-os como dissociados na prática. Este tipo de abordagem deu o tom de boa parte dos trabalhos acadêmicos da década de 1960, cuja interpretação sobre a relação entre biomedicina e medicinas populares se dava na chave
5 O conjunto de dados empíricos que fundamenta esta pesquisa é proveniente de trabalho de campo (observação e entrevistas, realizados com o consentimento dos interlocutores) em diferentes espaços por onde circulam as raizeiras e raizeiros da Articulação Pacari, como feiras, farmacinhas caseiras e comunitárias, universidades, encontros e congressos científicos. Além do trabalho de campo, foi realizada consulta documental (vídeos sobre detentores de ofícios tradicionais de cura, legislação sanitária, guias e manuais produzidos pela Agência Nacional de Vigilância Sanitária (ANVISA), publicações organizadas pela Articulação Pacari, resoluções da OMS, dentre outros). 
da resistência da cultura popular face à cultura erudita, focando nos mecanismos de dominação.

Esta ideia de que a interação entre o sistema de cura hegemônico e outras formas de atenção à saúde seria marcada predominantemente pela hostilidade e que as medicinas populares assumiam uma postura de resistência frente à pretensão de dominação da medicina científica não deixa de estar associada ao pressuposto - bastante difundido entre autores da década de 1960, 70 e 80 (MONTERO, 1985) - de que o contato entre as duas levaria à aceitação completa da biomedicina, resultando numa aniquilação dos saberes e práticas populares.

Estudos mais recentes (FLEISCHER, 2011; TONIOL, 2015; ATTUCH, 2006; ALMEIDA, 2014; SANTOS, 2007) procuraram, por meio de suas etnografias, desconstruir a ideia dessas diferentes medicinas como blocos monolíticos, ao mesmo tempo em que relativizaram o poder de "fagocitação" que foi atribuído à medicina científica ao demonstrar que o contato e a convivência entre sistemas terapêuticos diversos não leva a destruição de nenhum deles, embora reconheçam que estão hierarquicamente organizados. Diferente disso, o que estes autores parecem mostrar é que o contato produz arranjos particulares que merecem ser observados e analisados.

O que pretendemos ao trazer a contribuição desses autores é enfatizar uma perspectiva que privilegia a observação das imbricações entre práticas e saberes. Tendo em vista essas "conexões" entre conhecimentos e técnicas terapêuticas na prática destes atores, cabe destacar que o campo da cura, embora organizado por tensões que se expressam em termos de acusações e disputas, também se organiza em termos de integrações e intercâmbios de determinados conceitos e práticas. Vejamos agora mais de perto como isso se dá entre as raizeiras e raizeiros organizados em torno da Articulação Pacari.

\section{0 projeto de autorregulação}

\subsection{Evidência versus crença: uma controvérsia como pano de fundo}

Certa vez, durante uma série chamada "É bom pra quê", transmitida pela Rede Globo no seu programa Fantástico ${ }^{6}$, Drauzio Varella, um dos médicos mais reconhecidos no Brasil e cuja presença na mídia é frequentemente requisitada, declarou que a medicina à base de ervas era uma medicina do passado, que tratava com poções mágicas, enquanto a medicina científica era uma medicina do presente, fundada na evidência. Retomamos essa declaração como forma de demonstrar que, embora a produção antropológica tenha superado determinadas dicotomias em suas análises, ela continua operando para muitos dos profissionais do campo da saúde. Assim, tomaremos o médico Drauzio Varella somente como uma tendência dentro da controvérsia ${ }^{7}$ que se desenrola no campo médico científico acerca das evidências ${ }^{8}$.

Aqueles que compartilham da mesma opinião do médico criticam fortemente o uso de remédios à base de plantas como recurso terapêutico por alegarem que
6 A série foi ao ar em 2011.

7 Bruno Latour desenvolveu o conceito de controvérsia no interior de sua teoria do ator-rede, forjada a partir de seus estudos sobre controvérsias científicas. Embora estejamos empregando este termo, cabe alertar ao leitor que não faremos uso desta abordagem, uma vez que esta pesquisa não tem como objetivo fazer um mapeamento e análise da controvérsia acerca da eficácia e segurança dos fitoterápicos, apenas pretende deixar destacado que ela está presente como pano de fundo.

8 Para localizar este debate, cabe lembrar que a fitoterapia foi formalmente reconhecida em 2006 como um modo de atenção à saúde e incorporada como uma das práticas integrativas/complementares oferecidas na rede pública de saúde. Esse reconhecimento se deu por meio da Política Nacional de Plantas Medicinais e Fitoterápicos (PNPMF) e da Política Nacional de Práticas Integrativas e Complementares (PNPIC). 
eles não passaram por todas as etapas dos estudos clínicos que comprovem sua segurança e eficácia9. Os médicos que assumem este posicionamento contrário ao uso de plantas medicinais que não tenham ainda sua segurança e eficácia comprovadas cientificamente criticam não só a escassez de evidências científicas acerca deste assunto, mas também algumas formas de comprovação que recentemente foram formalmente certificadas, como a "tradicionalidade de uso"10. De acordo com um dos médicos entrevistados no programa "É bom pra que?", este método seria falho porque só trabalharia com os "casos de sucesso", ou seja, destacaria somente os casos em que determinada planta se mostrou eficaz para uma dada doença, deixando de lado aqueles casos em que ela teria fracassado. Drauzio Varella, por sua vez, acusa a vigilância sanitária de substituir os estudos clínicos pelo "uso tradicional ou por publicações em livros e revistas" como forma de comprovar a segurança e eficácia dos remédios à base de plantas. Em entrevista concedida à revista Época, qualificou o referido instrumento de "empirismo irresponsável" e chegou a recomendar, no programa que comandou no Fantástico, que "para tratar doenças, não tome nada que não tenha rótulo nem bula”. Ainda no mesmo programa, Drauzio Varella sugere que os médicos deveriam ser responsáveis por "separar o que é ciência do que é crendice".

Este breve mapeamento do debate foi apresentado para demonstrar que os saberes e as práticas das raizeiras e raizeiros da Articulação Pacari estão inscritos neste campo de disputas e algumas de suas integrantes vão defender publicamente ${ }^{11}$, como é o caso de Lourdes (farmacêutica e uma de suas sócio-fundadoras), a validade do uso tradicional como forma de assegurar a eficácia e segurança de plantas medicinais que seriam comprovadas por meio dos "testemunhos de cura" ${ }^{12}$. Adiante veremos como os critérios de segurança e eficácia vêm sendo pensados pelos membros dessa organização.

\subsection{Quando punhados viram gramas}

O Protocolo Comunitário Biocultural das Raizeiras do Cerrado (2014) reivindica que os remédios caseiros não sejam obrigados a se submeterem aos procedimentos científicos de validação para que sua comercialização possa ser autorizada. Investindo na ideia de autorregulação de seu ofício, os esforços dos membros da Articulação Pacari encontram-se voltados à demonstração de que a fabricação de remédios caseiros é abalizada por regras, fundamentos e lógica, embora oriundas de outra tradição cultural e espiritual. É interessante observar que a reivindicação de autorregulação imprime um largo espectro de regras que passam a normatizar as condutas nesse campo popular e são orientadas, de acordo com Lourdes, para garantir a segurança. Por um lado, a autorregulação obriga, de certa maneira, à padronização dos procedimentos gerais de produção destes remédios que, até então, dependera do conhecimento e estilo pessoal daquele que os produzia: a coleta, armazenamento, envasamento, utensílios utilizados passam a ser consideradas etapas necessárias do procedimento e sujeitas a um controle externo. Assim, a
9 Para mais detalhes sobre este debate, ver D’ Almeida (2018).

10 De acordo com a ANVISA, ele é aceito nas principais legislações internacionais (Canadá, União Europeia e México) e recomendado pela OMS desde a Conferência de Alma-Ata. No Brasil, está previsto na PNPMF e em algumas resoluções do órgão sanitário. Segundo Carvalho (2011, p. 218; 222), há quatro formas de comprovação de segurança e eficácia previstas na legislação brasileira. Uma delas se dá através de informações existentes na literatura científica. A OMS orienta que deve ser realizada uma extensa pesquisa bibliográfica sobre todas as evidências de eficácia divulgadas na literatura disponível (periódicos médicos e científicos, farmacopeias e artigos sobre remédios tradicionais). Somente se houver alguma lacuna nesses estudos é que se faz necessário realizar novos experimentos sobre eficácia, como estudos clínicos. Ainda de acordo com a autora, a legislação sanitária brasileira prevê a comprovação de segurança e eficácia por uso tradicional, desde que rígidos critérios sejam seguidos.

11 Em capítulos de livros e entrevistas.

12 Entrevista concedida à organização não governamental “Terra de Direitos". Lourdes ainda destaca que embora a tradicionalidade de uso tenha sido recentemente reconhecida como um critério de comprovação, a PNPMF não considerou neste processo a repartição de benefícios para os "detentores desse conhecimento tradicional", o que violaria os direitos dos povos e comunidades tradicionais. 
tentativa de implementar a autorregulação exige das raizeiras e raizeiros articulados uma mudança na maneira de produzir um remédio caseiro, atentando para procedimentos de limpeza e higiene, formas de manejo, local de armazenamento e fabricação dos remédios, envasamento, rotulagem e valoração monetária ${ }^{13}$.

A ideia de criar critérios próprios de regulação teria partido das raizeiras e raizeiros que participaram do curso de extensão denominado "Boas Práticas Populares de Manipulação e Manejo de Plantas Medicinais do Cerrado”. De acordo com informações disponíveis na Farmacopeia Popular do Cerrado (2009) ${ }^{14}$, esta capacitação e outras que se seguiram foram uma estratégia identificada pela Articulação Pacari para "fortalecer a ação desses grupos comunitários [de raizeiras e raizeiros]" que compartilhariam entre si um sentimento de insegurança por prestarem um "serviço informal de saúde à comunidade, sem o reconhecimento por políticas públicas" (2009, p. 44) e se sentiriam receosos com a possibilidade da vigilância sanitária fechar suas farmacinhas comunitárias, aplicar multas ou mesmo mover algum processo judicial contra seus responsáveis.

Esse curso foi realizado pela Universidade Católica de Goiás, por meio de seu "Laboratório de Plantas Medicinais do Cerrado", e sua coordenação estava a cargo de Lourdes, que, à época, atuava nesta instituição como professora convidada. Ocorreu em 2003, com duração de sete meses, e dele participaram diversas lideranças da Articulação Pacari. Segundo Lourdes, por meio desse curso, os participantes tiveram acesso aos distintos conhecimentos e práticas farmacêuticas, possibilitando a emergência de uma atitude de "diálogo de conhecimentos", que, conforme buscaremos demonstrar, vem produzindo uma mutação no caráter eidético do conhecimento da raizeira.

Uma das atividades do curso solicitava aos participantes que anotassem os procedimentos que adotavam nas suas farmácias, caseiras ou comunitárias. Pedindo que descrevessem os procedimentos de limpeza (se varriam, se passavam pano, se utilizavam água sanitária, etc.), os ingredientes e recipientes utilizados na fabricação e armazenamento dos remédios e matérias-primas, os procedimentos de coleta, o local da casa utilizado, entre outros questionamentos, o curso transmitia uma forma de objetivar a atividade tradicional que a transforma completamente. A ideia era que fossem anotados todos os procedimentos, desde a coleta até a comercialização para que, a partir daí, fossem coletivamente elaborados "critérios de controle de qualidade" para sua preparação $0^{15}$. Após esse curso, e como continuidade dele, teria sido promovido um intercâmbio entre os participantes que passaram a visitar uns aos outros a fim de conhecer os procedimentos adotados em suas farmacinhas comunitárias, suas condições de trabalho e suas dificuldades. Este intercâmbio tinha como objetivo, de acordo com Lourdes, possibilitar a continuidade na construção do projeto de "boas práticas de preparação de remédios caseiros e de manejo de plantas medicinais do Cerrado" 16 , a fim de garantir maior segurança aos raizeiros/as envolvidos com as farmacinhas comunitárias em atividade que corriam o risco de ser, a qualquer momento, "visitadas" pela vigilância sanitária. A iniciativa de elaborar os critérios de controle de qualidade, além de ter contribuído para promover um sentimento de segurança entre os raizeiros, teria despertado
13 Ao contrário dos remédios caseiros, os atendimentos prestados por elas não teria sido objeto de investimento semelhante.

14 Publicação organizada pela Articulação Pacari e que reúne os resultados de alguns anos de pesquisa popular junto às organizações comunitárias de raizeiras e raizeiros do cerrado com o objetivo de elaborar um registro dos conhecimentos tradicionais sobre o uso medicinal de plantas nativas desse bioma. Entre seus 262 autores estão raizeiros, raizeiras, representantes de farmácias caseiras e/ou comunitárias. Cabe ainda destacar que, por meio de solicitação da Articulação Pacari, o "Ofício de Raizeiras e Raizeiros no Cerrado" (Farmacopeia Popular do Cerrado) encontra-se em processo de instrução para registro junto ao Instituto do Patrimônio Histórico e Artístico Nacional (IPHAN) como bem imaterial. Processo nº 01450.010388/200615. Data: 06/09/2006. Estados: Goiás, Mato Grosso, Maranhão, Tocantins e Distrito Federal. 15 Os manuais de boas práticas consultados durante a pesquisa com finalidade comparativa recomendam que para que um documento deste tipo seja elaborado, é imprescindível a presença e participação daqueles diretamente envolvidos com uma determinada tarefa. Recomenda-se que sejam levantados, um a um, todos os procedimentos que envolvem uma determinada prática para, então, proceder à elaboração final do documento. Segundo a definição presente no "Guia Prático do Farmacêutico Magistral”, os manuais de Boas Práticas seriam "guias que determinam as políticas da farmácia relacionadas a questões éticas, técnicas e operacionais. O principal - e aquele exigido pela legislação vigente - é o Manual de Boas Práticas de Manipulação em Farmácia (BPMF), o qual estabelece os cuidados com todas as operações da farmácia para a garantia da qualidade dos produtos e serviços" (Conselho Federal de Farmácia, 2017, p. 6). 
esses grupos para a "necessidade da construção de uma proposta técnica ampla e politicamente articulada pela sociedade civil para a prática da medicina popular” (DIAS; LAUREANO, 2009, p. 45). É a essa proposta que os membros da Articulação Pacari atribuíram o nome de "autorregulação da medicina popular"17.

A segurança à qual Lourdes e o texto da Farmacopeia Popular do Cerrado se referem diz respeito não apenas ao sentimento de segurança que os raizeiros passaram a ter ao adotarem os "critérios de controle de qualidade", mas a segurança como um princípio que deve guiar todo o processo de fabricação de um remédio caseiro, devendo nortear desde a coleta da planta que vai ser transformada, passando pela sua fabricação, até sua indicação a uma pessoa doente (2009, p. 45). Embora extenso, é importante reproduzir um trecho desta Farmacopeia pelo nível de detalhamento acerca dos critérios que teriam orientado a garantia de segurança:

(...) essa segurança está sendo construída através de três critérios básicos:

- a qualidade de uma planta medicinal deve ser certificada pela sua história de origem, através da avaliação de todas as etapas pelas quais a planta passou desde o seu cultivo ou extrativismo sustentável, até o seu beneficiamento para ser transformada em remédio caseiro;

- $\quad$ as boas práticas populares adotadas dentro de uma farmacinha devem abranger desde os procedimentos para se preparar cada tipo de remédio caseiro, até as condições da estrutura da farmacinha e os equipamentos e utensílios utilizados;

- $\quad$ a indicação do uso de uma planta medicinal para se preparar um remédio caseiro, deve ser necessariamente validada pelo conhecimento tradicional, transmitido de geração em geração (DIAS; LAUREANO, 2009, p. 45).

É interessante observar como esse movimento de objetivação, categorização e racionalização dos procedimentos articulados em torno da ideia de segurança não é compreendido como antagônico ao respeito da tradição. Lucely, raizeira, quilombola e também uma das sócio-fundadoras da Pacari, explica que ela e seus familiares (de quem teria herdado seus conhecimentos), embora não tivessem ciência, já exerciam as boas práticas, com a diferença de que não recebiam este nome e ainda não se encontravam sistematizadas e escritas. Lourdes, por sua vez, adverte que elas não seriam padronizadas e que os grupos teriam sido encorajados a utilizar alternativas locais, como forma de respeitar a realidade das raizeiras e raizeiros. Segundo ela, a elaboração das boas práticas não significa que "cada um vá adotar um novo procedimento 'padronizado' que melhor se 'adapte' aos regulamentos da vigilância sanitária”, e que teria sido pensada como forma de garantir a segurança na preparação desses remédios, sem desrespeitar as práticas tradicionais destas raizeiras e raizeiros.
16 Boas práticas podem ser elaboradas para uma gama enorme de atividades de diferentes ramos: boas práticas de ordenha; boas práticas de fabricação de alimentos; boas práticas de fabricação de medicamentos; boas práticas clínicas, boas práticas laboratoriais, dentre outras.

17 As Boas Práticas de Fabricação e a Farmacopeia Popular do Cerrado são dois de seus resultados. 
Ainda de acordo com Lourdes, as boas práticas têm "um conteúdo político e voltado para o reconhecimento de nossa diversidade cultural. O que importa é fortalecer a tradicionalidade de uso, as boas práticas da cultura e da tradição, que possuem qualidade, segurança e eficácia”. Seu relato aponta para a preocupação em assegurar a continuidade das práticas de cura e cuidado destas raizeiras e raizeiros que, aqui, são tomadas como expressões da diversidade cultural brasileira. Assim como Lucely, Lourdes também expressa seu entendimento de que os princípios que orientam as boas práticas já se encontravam presentes no cotidiano do ofício - "as boas práticas da cultura e da tradição" - acrescentando que elas também permitem assegurar qualidade, eficácia e segurança, ou seja, uma percepção que contrasta radicalmente com a ideia de que os estudos clínicos seriam a única forma legítima de atestar esses critérios.

A preocupação com o respeito à tradição e à particularidade dos "modos de fazer" de cada raizeira que se encontra presente no projeto de autorregulação, também foi explicitada no seguinte trecho da Farmacopeia Popular do Cerrado:

A elaboração de critérios para as atividades de uma farmacinha não deve interferir na diversidade cultural dos 'modos de fazer' e, principalmente não deve modificar as receitas tradicionais dos remédios caseiros. Os 'modos de fazer' as atividades da farmacinha devem ser avaliados, melhorados, ordenados passo a passo e registrados, para que sua reprodução seja feita dia a dia, resultando na melhoria do controle de qualidade dos remédios caseiros preparados e garantindo a transmissão do conhecimento (DIAS; LAUREANO, 2009, p. 49).

Ao concebê-lo como um projeto de autoria coletiva e que respeita as especificidades das raizeiras, Lourdes entende ser importante que, nesses encontros, fossem definidas orientações gerais acerca de "algumas coisas" que não deveriam ser feitas ou utilizadas, ainda que não tivessem caráter impositivo. Cita como exemplo a utilização da panela de alumínio para a fabricação de alguns remédios. Os participantes teriam acordado que esse tipo de panela não era adequado, no entanto, não teriam definido uma única alternativa que pudesse substituir seu uso, tendo sido encorajados ao uso de alternativas disponíveis no local, aquelas que seriam de uso diário das raizeiras, tais como: panelas esmaltadas, de barro, de ferro e colheres de pau.

Uma das recomendações encontradas no livro Pesquisa popular com plantas medicinais (2004, p. 52) ${ }^{18}$ para a preparação dos remédios caseiros diz o seguinte: "as colheres, panelas, canecas ou bules de alumínio não são indicados, porque o alumínio pode interferir na composição do remédio e, consequentemente, na sua qualidade. Sugere-se usar colheres de madeira e vasilhas esmaltadas, de inox ou de vidro".

As principais orientações para garantir a segurança na produção de remédios caseiros foram reunidas nesse curso num documento denominado como POP-POPs - Procedimentos Operacionais Padronizados Populares. Trata-se de uma re-
18 Organizado pela Articulação Pacari e Rede de Intercâmbio de Tecnologias Alternativas (REDE). 
ferência ao Procedimento Operacional Padrão (POP), que, assim como os manuais de boas práticas, é um documento exigido pela ANVISA e que consiste, conforme definição oficial, num "procedimento escrito autorizado fornecendo instruções para a realização de operações não necessariamente específicas a um dado produto ou material, mas de natureza geral, tais como operação, manutenção e limpeza de equipamentos, validação, limpeza de instalações e controle ambiental, amostragem e inspeção" (BRASIL, 2015, p. 199). Dito em outras palavras, os POPs correspondem à descrição pormenorizada de técnicas e operações que envolvem a rotina de um laboratório e/ou indústria farmacêutica e que contêm instruções de como proceder em cada atividade, visando proteger e garantir a preservação da qualidade das preparações manipuladas e a segurança dos manipuladores. Tanto os POPS quanto os manuais de boas práticas teriam como finalidade "orientar cada procedimento, bem como possibilitar a comprovação de todos os atos executados. Dessa forma, permite a rastreabilidade dos processos com o intuito de aprimoramento contínuo" (Conselho Federal de Farmácia, 2017, p. 6).

A percepção de que as normas e recomendações de higiene exigidas pela Anvisa seriam inexequíveis levando-se em consideração os contextos de produção dos remédios caseiros ${ }^{19}$ teria levado o grupo a trabalhar na adaptação desses critérios oficiais à realidade das raizeiras e raizeiros e a acrescentar um novo $\mathrm{P}$, de popular. Adotaram-no com o mesmo objetivo: conferir segurança e qualidade aos remédios caseiros e à sua prática de fabricação, de maneira a evitar que ocorram variações nos procedimentos e, também, reduzir os riscos de multas e/ou fechamento das farmacinhas comunitárias. O fato da produção e comercialização de remédios caseiros serem consideradas práticas ilegais (por carecerem de estudos científicos que atestem sua segurança e eficácia), teria sido a razão, segundo consta no Protocolo Comunitário Biocultural das Raizeiras do Cerrado (2014), que motivou a criação dos critérios de boas práticas populares.

A partir da descrição que cada participante do curso teria feito dos procedimentos de fabricação de seus remédios, reuniu-se um conjunto de critérios e recomendações que passaram a organizar as distintas etapas que envolvem este processo, desde a coleta até o produto pronto. Lourdes explica que a elaboração das "boas práticas" teve inspirações diversas, mas que a principal teria sido o convívio com as raizeiras que teria revelado que elas "sempre tiveram boas práticas" na fabricação de seus remédios caseiros. De acordo com ela, estas boas práticas foram observadas no cotidiano do ofício, em diversos momentos: "tanto a higienização, porque o asseio para fazer um remédio caseiro é o mesmo que temos ao preparar nossa comida; na responsabilidade de preparar uma receita tendo como base o conhecimento tradicional; e a segurança de identificar a planta medicinal, tendo sempre a certificação de uma raizeira mais velha sobre a identificação da planta a ser usada”. Todo este repertório que, conforme é colocado por ela, já fazia parte quase que naturalmente da bagagem das raizeiras antes mesmo que fossem reunidos sob esta designação, teria conferido segurança às mesmas para sistematizarem seus próprios procedimentos. Além de tomar a prática cotidiana das raizeiras como principal fonte de inspiração, Lourdes diz, embora com me-
19 Foi mencionada, como exemplo, a exigência de que seja utilizada água sanitária para fazer a limpeza do chão, o que se mostra inviável quando se trata de chão de terra batida. 
nor destaque, que também teriam sempre procurado tomar conhecimento de documentos, recomendações e referências técnicas sobre saúde, entre elas as publicadas pela Organização Mundial da Saúde.

Para as raizeiras e raizeiros articulados, produzir um remédio de qualidade significa, hoje, observar os preceitos das "boas práticas" de uso e manejo das plantas medicinais que foram definidos. Lucely explica que seu emprego permite garantir, independente da planta utilizada (uma vez que podem ocorrer variações na disponibilidade da espécie em função da região onde se encontra a raizeira), e do lugar onde ela estiver, que os remédios produzidos por ela possuem a mesma qualidade que aquele produzido por outra raizeira da Articulação Pacari residente em outro estado.

Segundo consta no Protocolo Comunitário Biocultural das Raizeiras do Cerrado, este empreendimento conjunto tinha como objetivo:

demonstrar que a preparação de remédios caseiros não é feita de forma aleatória e obedece a critérios de boas práticas populares, desde a coleta da planta até o remédio pronto, fundamentados principalmente no conhecimento tradicional e na experiência das raizeiras (...) (DIAS; LAUREANO, 2014, p. 18).

A partir das informações levantadas nas conversas informais e entrevistas com as raizeiras e raizeiros, bem como da observação de campo e consulta às publicações organizadas pela Articulação Pacari, foi possível reunir esse conjunto de orientações, a princípio dispersas, em torno de alguns critérios centrais. Vejamos a seguir cada um deles.

\section{Critérios de higiene}

A ideia em reservar um espaço próprio para o armazenamento dos remédios caseiros foi um critério acordado, e seu emprego, na prática, pôde ser observado no trabalho de campo. As farmacinhas caseiras e comunitárias visitadas possuem um espaço próprio destinado ao armazenamento das plantas medicinais, dos remédios prontos e dos utensílios utilizados em sua fabricação. No caso das farmacinhas caseiras, a preparação dos remédios costuma ser feita na própria cozinha da casa e as comunitárias contam com uma cozinha utilizada exclusivamente para esse fim. Como dito anteriormente, um dos critérios de boas práticas se refere à higiene pessoal da raizeira e do raizeiro. Neste sentido, ficou estabelecido entre seus membros que toucas e aventais devem ser utilizados e que as mãos devem ser mantidas limpas durante o preparo e a manipulação dos remédios. Com relação ao ambiente (ou ambientes) onde se dá o processo de fabricação, acordou-se que os mesmos deveriam ser mantidos limpos, e os materiais e utensílios utilizados deveriam ser esterilizados. A fim de evitar a proliferação de insetos e moscas, recomenda-se que seja feito um controle destes insetos e que o lixo produzido 
receba uma destinação adequada.

No livro Pesquisa popular de plantas medicinais constam também recomendações quanto à higiene do local e dos materiais utilizados durante o processo de preparação do remédio e que, segundo consta, seriam importantes na garantia de sua qualidade (2004, p. 52). A presença de superfícies laváveis, como pisos, paredes e bancadas; banheiro em boas condições de uso; locais próprios para armazenar insumos, embalagens e plantas; presença de forro no teto; ausência de umidade e mofo nas paredes foram igualmente descritos na Farmacopeia Popular do Cerrado como critérios relevantes na garantia da qualidade e segurança dos remédios caseiros (2009, p. 48).

\section{Critérios de coleta e manejo}

Os cuidados na coleta e no armazenamento das plantas também teriam sido objeto de debate. Nos cursos, os membros da Articulação Pacari teriam trabalhado na elaboração do que chamaram de um plano de manejo para as plantas medicinais do cerrado, cujo objetivo seria garantir a preservação do meio ambiente por meio de acordos quanto aos procedimentos de coleta. A preocupação com esta etapa se justifica por duas razões: uma delas é garantir, por meio do emprego de técnicas sustentáveis, o manejo adequado para que a natureza se mantenha preservada. A outra é assegurar a eficácia e segurança do remédio fabricado por meio da identificação botânica correta da planta.

No que concerne à primeira, alguns cuidados são observados no processo de extração das plantas medicinais, como, por exemplo, retirar aquelas que serão utilizadas dos galhos, não extrair a casca do tronco da planta, não desmatar o seu entorno, ater-se apenas à quantidade necessária para fazer o remédio, dentre outros. Lucely, uma das interlocutoras da pesquisa, avalia este conjunto de técnicas da seguinte maneira:

a gente tem todo um cuidado com o cerrado, um cuidado com a natureza, um respeito com a natureza. Então, isso que é a nossa diferença. Se a gente vai coletar uma planta, a gente coleta em galho, você não tira a casca do tronco da planta. Então, a gente tem toda uma lei sustentável para você ter aquela árvore ali durante muitos e muitos anos e passar até de geração para geração. (...) Além de você ter o seu remédio, você tem a preservação das espécies (...).

No que diz respeito à segunda, no livro Pesquisa popular com plantas medicinais, encontram-se recomendações que chamam a atenção para a importância de se conhecer o local de procedência da planta, descartando-se aquelas cultivadas em lugares poluídos, próximos de ruas, estradas e esgotos. Esses critérios que orientam a coleta e manejo das plantas medicinais teriam sido definidos pelas raizeiras e raizeiros como indicadores de qualidade dos remédios que produzem. Orientação 
semelhante é encontrada na Farmacopeia Popular do Cerrado ao descrever alguns indicadores que devem ser considerados no momento de avaliar a qualidade das plantas cultivadas em hortas e quintais, como: proximidade às fossas sanitárias, presença de animais domésticos, proximidade às rodovias com exposição a gases de automóveis, qualidade da água de irrigação, entre outros (2009, p. 47).

Ainda em relação aos cuidados que devem ser tomados nesta etapa, as raizeiras e raizeiros interlocutores dessa pesquisa ressaltaram que para se ter uma planta de qualidade, é necessário que se esteja atento ao horário da coleta que, preferencialmente, deve ocorrer pela manhã ou no final do dia, pois seriam os momentos em que a concentração do princípio ativo estaria mais alta. Da mesma forma, uma raizeira pontuou que não se deve fazer a coleta com chuva, pois isso também interferiria em sua concentração. A lua seria outra variável responsável por influenciar na qualidade e durabilidade da matéria-prima. Por esse motivo, é recomendado evitar coletar raízes na lua nova e cheia, pois em dois meses ela “enche de bicho" e já não é mais utilizável. A lua minguante seria o período ideal para se coletarem raízes, conforme explicação de Lucely, pois estariam com o "princípio ativo bem forte" e a raiz teria uma durabilidade maior, de aproximadamente seis meses. Raizeiras e raizeiros salientam também a importância de se adotarem procedimentos para que se possa obter uma "planta de boa qualidade", como: lavar bem as folhas, fracioná-las, colocá-las para desidratar na sombra, em local limpo e ventilado e, só depois, armazená-las. Todas estas precauções seriam importantes para evitar que as plantas fiquem mofadas e, assim, prejudiquem a qualidade e segurança do remédio.

Explicitar o caminho percorrido pela planta, desde sua coleta até a disposição do remédio pronto nas farmacinhas, seria uma maneira de demonstrar que o processo é orientado por critérios de boas práticas e que a qualidade do remédio caseiro está assegurada. Esta rastreabilidade ${ }^{20}$, conforme definição presente no Protocolo Comunitário Biocultural das Raizeiras do Cerrado, permitiria assegurar três coisas: a identificação botânica correta da planta; a adoção de técnicas sustentáveis no momento da coleta; e o cumprimento dos critérios que envolvem seu processamento (lavagem, secagem, fracionamento, etc.) (2014, p. 18).

Somada a isso, foi recomendada a adoção de pesos e medidas nas receitas dos remédios caseiros. De acordo com Lucely, ela e seus familiares (tios, tias, primos e primas) ainda trabalham com fórmulas herdadas de seu tataravô e, recentemente, eles vêm convertendo os "punhados” das receitas do ancestral em gramas.

Além da conversão dos "punhados" em gramas, puderam ser observadas outras técnicas que conferem maior precisão ao processo, como, por exemplo, a adoção do medidor de pH utilizado para medi-lo nos xampus e sabonetes fabricados.

\section{Critérios de armazenamento, rotulagem e venda}

Com vistas a garantir uma maior durabilidade aos extratos e não provocar interferência em sua composição, teria sido acordado que o vidro âmbar deveria
20 Foi possível observar que este novo léxico não é absorvido pelas raizeiras e raizeiros articulados com a mesma intensidade. Estes termos encontram-se presentes com maior frequência nas publicações organizadas pela Articulação Pacari e, com exceção do "princípio ativo", menos presente nas conversas cotidianas. Isso mostra a distância entre a organização deste modelo e sua apropriação nas práticas, deixando à mostra que quanto mais perto do "centro", mais a raizeira ficará próxima a esse modelo, e quanto mais isolada, mais distante. Neste sentido, parece tratar-se de um processo de construção de um modelo para as práticas (sendo ele também um tipo de prática), mas não, necessariamente, as práticas elas mesmas. 
substituir o uso de garrafas de plástico, potes de maionese e outros recipientes considerados inadequados para seu armazenamento. Quanto aos xaropes, esses deveriam ser colocados em recipientes de vidro de $100 \mathrm{ml}$, volume que foi considerado conjuntamente pelos participantes do curso como suficiente para promover uma melhora e cura no período de uma semana. Afinal, como conclui Aparecida, "entendeu-se no curso de boas práticas que a pessoa precisa se tratar com $100 \mathrm{ml}$ de xarope, então, por que o outro vai levar um vidro de 300?"

Esta quantidade teria sido considerada exagerada, tendo em vista que os xaropes não levam conservantes, podendo se deteriorar quando armazenados por um longo período e visaria também evitar a prática de alguns raizeiros de envazar os xaropes em potes de maionese e garrafas de $1 / 2$ litro. Aparecida comenta que ao comparar fotos antigas dos encontros promovidos pela Articulação Pacari com algumas mais atuais fica evidente a mudança: nas antigas seria possível observar uma variedade enorme de utensílios nos quais eram armazenados os xaropes, enquanto nas mais recentes se observa que todos estão em vidros de $100 \mathrm{ml}$.

No que se refere aos extratos, teria sido acordado que os mesmos deveriam ser envazados em vidros de 20 e $30 \mathrm{ml}$ e vedados com tampa-lacre. Assim como os insumos e todos os outros remédios nas mais diferentes formas, os extratos deveriam ser protegidos da luz, motivo que explica sua acomodação nos cômodos mais escuros da casa e das farmacinhas comunitárias.

O processo de rotulagem deveria obedecer a critérios como, por exemplo, a não indicação do remédio no rótulo, a fim de evitar a automedicação. O ideal seria que, antes de indicar um remédio, a raizeira ou raizeiro conversasse com a pessoa, perguntando o que ela está sentindo, se já teria passado por exames, se já havia procurado um médico, se tomava outros medicamentos de uso contínuo, etc.

Por fim, teria sido acordado entre os participantes que os remédios caseiros deveriam ser vendidos a um preço justo, o que significa atribuir um valor aos remédios para que possam, pelo menos, cobrir os custos que envolvem sua produção e garantir a subsistência dos raizeiros e raizeiras. Para que seja considerado justo, tais valores não devem extrapolar este cálculo, uma vez que o propósito desta prática, tal como vem sendo proposto pelos membros da Pacari, não deve ser a aquisição de lucro, mas a prestação de ajuda àqueles que necessitem.

\section{Critérios de comprovação de segurança e eficácia}

Por meio do que foi descrito até aqui, podemos observar que a formulação destes diversos critérios aponta para um investimento no sentido de racionalizar e uniformizar práticas díspares. Vemos, ainda, que o universo das práticas de produção de remédios caseiros incorporou para si a ideia de que seguir protocolos de seleção de matéria-prima e cuidados na produção são essenciais para a segurança do produto. Já no que diz respeito à criação de protocolos de comprovação de sua eficácia, a questão se torna um pouco mais complexa. Embora a ideia de que é necessário comprovar a eficácia esteja presente hoje no universo das práticas de 
produção dos remédios caseiros, ela assume sentidos bastante particulares nesse contexto. Os critérios privilegiados para a comprovação de sua segurança e eficácia não passam pelos critérios típicos de comprovação do campo científico, como levantamento de bibliografia acadêmica e ensaios clínicos. Diferente disso, eles enfatizam a criação de mecanismos de rastreabilidade e os testemunhos de cura dos usuários como forma de enfrentar esta demanda. Deste ponto de vista, o fato de um remédio poder ser rastreado significa que suas origens e formas de preparo estão submetidas a determinados critérios e podem ser averiguadas, conferidas, comprovadas, validadas. Essa busca pela transparência no processo de produção parece ter como objetivo demonstrar que a preparação de um remédio caseiro não corresponde a algo "obscuro", "mágico" ou aleatório.

Já os testemunhos de cura, como o próprio nome sugere, são testemunhos de usuários que, ao afirmarem publicamente terem sido curados, validariam tanto o conhecimento terapêutico das raizeiras e raizeiros como a eficácia e segurança de seus remédios. Na Farmacopeia Popular do Cerrado (2009) encontra-se sublinhada a importância de registrar as informações geradas nas farmacinhas - como o número de pessoas atendidas por mês e as respectivas doenças diagnosticadas - como indicadores do perfil epidemiológico de uma determinada comunidade. O registro do número de pessoas atendidas e curadas também seria de grande relevância enquanto instrumento de demonstração da eficácia dos remédios produzidos e da identificação correta, pelas raizeiras e raizeiros, das plantas utilizadas na sua composição (2009, p. 49). O registro destas informações é colocado como um desafio para os autores do texto, uma vez que, segundo consta, as raizeiras que trabalham nas farmacinhas não têm a prática de registrar os "dados de eficácia" dos seus remédios, pois as curas são divulgadas oralmente através dos testemunhos. Seria esta dinâmica de experimentação e confirmação do conhecimento das raizeiras acerca das fórmulas dos remédios, do diagnóstico de doenças e seus processos de cura no cotidiano das farmacinhas que permitiria concebê-las como "verdadeiros laboratórios culturais" (2009, p. 49).

Diante da constatação desta escassez de registros escritos que comprovem a segurança e eficácia dos remédios caseiros ${ }^{21}$, a Farmacopeia pretende ser um instrumento de validação do conhecimento de raizeiras e raizeiros sobre as plantas medicinais nativas, ao passo que também contribuiria para a superação desta lacuna no conhecimento que, por sua vez, já foi amplamente destacada pela OMS.
21 De acordo com o que consta descrito nessa obra, ela teria como objetivo "ser uma referência teórica para a segurança de indicação dos remédios caseiros".

\section{Movimento em direção à Ciência}

Vemos, pois, que os preceitos pactuados na Articulação Pacari se apropriam da ideia de higiene e das prescrições sugeridas pela autoridade sanitária para validar suas práticas como confiáveis, transparentes e asseguradas mais no conhecimento da natureza do que nos poderes mágicos. No entanto, no plano da demonstração da eficácia, retornam ao plano da retórica religiosa do testemunho - experiência pessoal, não verificável e/ou reprodutível; isto é, este tipo de "de- 
monstração" se realiza no plano da "fé" ou da "persuasão". É a questão da "segurança" e "eficácia" do remédio caseiro que, ao dissociar-se dos critérios científicos de validação, aloca essas práticas na periferia do sistema de saúde, tornando-as mais próxima das "crenças populares" do que da medicina.

A prática das raizeiras e raizeiros, ao contrário, aponta num sentido inverso. Ao acordarem critérios que confiram segurança e qualidade, elas indicam uma aproximação com o código biomédico e o universo científico. Conceitos que têm a ver com a própria história da medicina ocidental, como eficácia, segurança, higiene (BUCHILLET, 1991) são transplantados para os contextos em que estão inseridas. Os testemunhos de cura parecem ser o único recurso de comprovação que foge das formas de regulamentação propostas pela Ciência, apesar de estarem a serviço da comprovação.

Observação semelhante foi feita por Araújo (2002) ao identificar que a equipe biomédica responsável pelo projeto de inserção da fitoterapia na rede municipal de saúde de Londrina projetava sobre essa prática terapêutica o modus operandi da biomedicina. A autora demonstra que a "recuperação" do conhecimento de cura popular teria ocorrido de forma fragmentada e pontual, uma vez que teria sido despido de todo o significado de seu contexto de origem. Neste sentido, a dimensão mágico-religiosa teria sido neutralizada com o objetivo de atrair respeitabilidade científica para a fitoterapia.

De forma semelhante ao que foi observado pela autora com relação à fitoterapia, as raizeiras e raizeiros da Articulação Pacari, ao intercambiar conceitos e práticas com o universo científico, conferem uma maior legitimidade às suas práticas e saberes sobre cura ${ }^{22}$. Contudo, vale ressaltar que este movimento não é desprovido de questionamentos e tensões; ao contrário, é feito a partir de críticas, triagens, combinações e ressignificações que resultam numa síntese original que não estava prevista anteriormente.

No caso da Articulação Pacari, ao formularem critérios procedimentais próprios e buscarem conferir transparência a todo o processo de produção - o que entendemos ser uma racionalização de suas práticas - essas agentes estariam afastando suas práticas terapêuticas - ainda que de forma não enunciada - do estigma da magia, da superstição, do obscuro, rótulos que foram historicamente utilizados para qualificá-las e tiveram como implicação o não reconhecimento de suas práticas enquanto práticas médicas. Proceder desta maneira seria uma forma de se legitimarem no campo da saúde e produzirem um novo lugar social para seu ofício, que, assim como sua prática demonstra, empresta elementos reconhecidos como científicos, mas não abandona por completo um quadro de referência que é fornecido pela religião ou espiritualidade. Conforme sintetizou Lourdes, "nossa matéria-prima é planta medicinal e outros componentes de fé, solidariedade, espiritualidade e ancestralidade". A preparação espiritual foi, com frequência, enfatizada pelas raizeiras e raizeiros como um dos atos que envolvem seu ofício, sendo descrita também em seu Protocolo Biocultural (2014) ${ }^{23}$. Ela antecederia sua entrada na área de coleta das plantas, a preparação dos remédios e o atendimento de saúde prestado (2014).
22 É importante esclarecer que estamos nos debruçando sobre os intercâmbios com o universo que é entendido como científico, contudo, dinâmica semelhante foi observada em relação a outros repertórios de cura e cuidado. Um exemplo é o recente aprendizado das raizeiras de uma farmacinha comunitária no interior de Minas Gerais sobre a "técnica do pêndulo" no diagnóstico dos males e com o qual tiveram contato por meio de uma missionária reconhecida na cidade pelos atendimentos de saúde que presta.

23 Segundo consta neste documento, esta preparação consiste em uma "troca espiritual com a natureza, de energia e purificação" (2014, p. 11). No livro Ervanário São Francisco de Assis (2003), cuja autoria é do casal de raizeiros associados à Articulação Pacari - Aparecida e Fernando - e dedicado a narrar suas trajetórias, é também enfatizada a importância da preparação antes da fabricação do remédio, só que neste caso, encontra-se designada pelo termo "higiene mental ou espiritual (2003, p. 37). 
Rodrigo Toniol (2012; 2015), em seus trabalhos sobre medicinas alternativas e complementares, descreveu um processo que guarda semelhanças e, ao mesmo tempo, particularidades com o que estamos descrevendo. De acordo com o autor, após a promulgação da PNPIC, o termo "terapias alternativas" foi, progressivamente, substituído por "práticas complementares e integrativas". Tal mudança na nomenclatura teria se dado em função da pressão exercida por intelectuais e dos próprios terapeutas que, através dela, procuraram se desvencilhar da associação entre suas práticas e religião. Outro recurso que os defensores das práticas integrativas e complementares teriam encontrado para legitimarem-na diante de determinados grupos teria sido a produção de pesquisas clínicas com o objetivo de apresentar as terapêuticas complementares/integrativas oferecidas no SUS em termos biomédicos, procedimento que demonstraria o interesse pelas provas $d a$ eficiência do tratamento (TONIOL, 2012, p. 8). Diante do que foi descrito, o autor conclui que tanto a estratégia de mudar a nomenclatura quanto a preocupação em apresentar provas de eficiência foram formas encontradas por esses terapeutas de escapar de uma classificação religiosa e se aproximarem da ciência. Nota-se, então, que as dinâmicas descritas pelo autor se assemelham às observadas entre as raizeiras e raizeiros articuladas, na medida em que é possível identificar uma aproximação da ciência em ambos os casos. Contudo, elas se diferem porque, ao contrário dos terapeutas holísticos, estas raizeiras e raizeiros não pretendem se afastar da religião. A declaração de Dona Francisca (raizeira, parteira, benzedeira e membro da Pacari) no $1^{\circ}$ Congresso Internacional de Práticas Integrativas e Complementares e Saúde Pública ${ }^{24}$ é emblemática neste sentido. O conteúdo de sua apresentação esteve voltado principalmente para destacar a importância do cuidado nos atendimentos de saúde e, com frequência, ela se referiu a Deus, Jesus, ao bem comum, ao respeito e ao imperativo de ajudar o próximo. Ao abrir a mesa, mencionou que se sentia muito orgulhosa por estar naquele congresso "testemunhando o Deus verdadeiro que está na nossa casa nos incentivando a nos reunir para fazer o bem para as pessoas. Temos que lutar por essa causa [se refere ao SUS]"25.

Sua declaração, bem como a de Lourdes, reproduzida acima, e a importância que estas raizeiras e raizeiros atribuem à preparação espiritual no cotidiano de seu ofício apontam justamente para o não abandono deste quadro de referência.

Por fim, cabe sublinhar que, embora as raizeiras e raizeiros da Articulação Pacari reivindiquem o reconhecimento oficial do Estado, elas não vislumbram com a autorregulação sua inserção no SUS, seja a sua enquanto agentes de saúde, seja a de seus remédios. Quando questionada se havia interesse por parte dos membros da organização em atuar no SUS por meio da concessão de carteirinhas, tal como ocorreu com as benzedeiras do interior do Paraná, Lourdes respondeu negativamente e complementou:

nós lutamos para assegurar o direito de ser raizeira e, como tal, praticar o atendimento de saúde nas comunidades locais. (...) O nosso trabalho é de resistência, para que nossos conhecimentos tradicionais associados ao
24 Realizado no Rio de Janeiro, em 2018. Dona Francisca era uma das convidadas da mesa-redonda "Tradição e inovação no gestar, no parir e nascer", que debatia sobre a assistência materno-neonatal. 250 tom dos outros palestrantes que dividiam a mesa com ela não foi muito diferente, embora não tenham feito referências a Deus. 
uso de plantas medicinais permaneçam vivos, porque fazem parte de nossa tradição, de nossa cultura, de nosso costume, de nossa sobrevivência. (...) Então, não é o caso de querermos inserir os remédios caseiros no SUS. Não atendemos à legislação que existe, que exclui este tipo de tratamento e de remédio nas prescrições médicas. Para isso foi formulada a Política de Práticas Integrativas e Complementares que reconhece as práticas dos terapeutas que praticam a medicina tradicional vinda de outros países como China, Índia... Mas a nossa medicina tradicional, praticada nas comunidades tradicionais, em todo o Brasil, esta não é reconhecida ainda. Nem os remédios caseiros, porque não obedecem à legislação da ANVISA. Então, não lutamos por isso, lutamos para continuarmos a existir como raizeiras, em nossas comunidades, sem que esse ofício tradicional seja criminalizado.

Assim, o que pretendem as raizeiras e raizeiros organizados em torno da Articulação Pacari é o reconhecimento legal de sua atividade enquanto uma forma tradicional de medicina. Para Lourdes, o projeto de autorregulação tem como um de seus objetivos valorizar e assegurar as práticas tradicionais das raizeiras como um direito - consuetudinário, segundo seu pleito -, além de ser uma estratégia para a proteção dos conhecimentos tradicionais. Diferente do que ocorreu com as práticas integrativas e complementares, que foram institucionalizadas e vêm sendo reguladas, estas raizeiras e raizeiros não anseiam por sua inserção nos sistemas públicos de saúde. Afinal, institucionalizar significa regular, monitorar e definir quem está e quem não está apto a exercer uma determinada prática de cura, ferindo qualquer pretensão de autonomia.

\section{Considerações finais}

Buscamos demonstrar a maneira como foi construída a autorregulação, chamando a atenção para a incorporação de práticas e conceitos comumente associados ao campo científico, sinalizando, assim, para uma aproximação com este universo. Esta dinâmica é empreendida visando ao fortalecimento de sua posição num campo dominado por disputas pela legitimidade de práticas e saberes de cura e no qual a biomedicina vem ocupando, há pelo menos um século, o topo da hierarquia e detendo o monopólio da autoridade de fala. Contudo, ao mesmo tempo em que se movem nesta direção, estas raizeiras e raizeiros articuladas não parecem inclinadas a abandonarem outras influências que compõem suas trajetórias. Assim, este projeto nos fornece a concretude da articulação entre elementos provenientes de diversos repertórios. Por esta razão, suas práticas constituem caso exemplar que nos desafia a compreender a complexa dinâmica implicada nas relações entre os diferentes sistemas terapêuticos que acabam por produzir novos personagens, novos saberes e novas formas de articulação entre eles. Sem pretender classificar suas práticas como mais próximas da magia ou da ciência, da persuasão ou da comprovação, procuramos entendê-las como múltiplos orde- 
namentos da realidade, conforme proposto por Tambiah (1990).

Nota-se também que a participação de uma farmacêutica, também sócio-fundadora da Articulação Pacari e ex-professora universitária, é peça-chave para se compreender o desenho específico que esse projeto ganhou, apontando para o papel dos mediadores, tal como formulado por Montero (2006). São eles, em certa medida, que colocam em circulação categorias, noções e objetos com os quais tomaram contato em virtude de seu trânsito por diversos universos (acadêmico-científico, político, jurídico) e escalas (local, nacional e internacional). Tais elementos e referências, como vimos, são apropriados pelas lideranças desta organização de uma maneira muito particular, atribuindo a eles significados específicos que possam ir ao encontro de suas reivindicações.

Recebido: 23/07/2020

Aprovado: 02/10/2020 


\section{Referências}

ALMEIDA, Juliano Florczak. Bom Jardim dos Santos: trazendo as plantas de volta à vida (fluxo dos materiais e religiosidades populares em Guarandi das Missões, RS). Dissertação (Mestrado em Antropologia Social] - Universidade Federal do Rio Grande do Sul, Porto Alegre, 2014.

ARAÚJO, Melvina Afra M. de. Das ervas medicinais à fitoterapia. São Paulo: Ateliê Editorial; FAPESP, 2002.

ATTUCH, lara Monteiro. Conhecimentos tradicionais no Cerrado: sobre a memória de Dona Flor, raizeira e parteira. Dissertação (Mestrado em Antropologia) - Universidade de Brasília, Brasília, 2006.

AUÊ. Ervário São Francisco de Assis, 2003.

BRASIL. Agência Nacional de Vigilância Sanitária. Compilado de procedimentos do Sistema Nacional de Vigilância Sanitária. Brasília: ANVISA, 2017.

BRASIL. Agência Nacional de Vigilância Sanitária. Consolidado de normas da COFID (Versão V). Brasília: ANVISA, 2015.

BRASIL. Agência Nacional de Vigilância Sanitária. Guia de orientação para registro de medicamento fitoterápico e registro e notificação de Produto Tradicional Fitoterápico. Brasília: ANVISA, 2014.

BRASIL. Ministério da Saúde. Agência Nacional de Vigilância Sanitária. Resolução $R D C N^{\circ} 13$, de 14 de março de 2013. Dispõe sobre as boas práticas de fabricação de produtos tradicionais fitoterápicos. Disponível em: http://bvsms.saude.gov.br/bvs/ saudelegis/anvisa/2013/rdc0013_14_03_2013.html. Acesso em: 26 abr. 2020.

BRASIL. Ministério da Saúde. Agência Nacional de Vigilância Sanitária. Resolução - RDC $N^{\circ} 17$, de 16 de abril de 2010. Dispõe sobre as Boas Práticas de Fabricação de Medicamentos. Disponível em: http://portal.anvisa.gov.br/documents/33880/2568070/ res0017_16_04_2010.pdf/b9a8a293-f04c-45d1-ad4c-19e3e8bee9fa. Acesso em: 26 abr. 2020.

BRASIL. Ministério da Saúde. Agência Nacional de Vigilância Sanitária. $R D C N^{\circ} 26$, de 13 de maio de 2014. Dispõe sobre o registro de medicamentos fitoterápicos e o registro e a notificação de produtos tradicionais fitoterápicos. Disponível em: http://bvsms. saude.gov.br/bvs/saudelegis/anvisa/2014/rdc0026_13_05_2014.pdf. Acesso em: 26 abr. 2020.

BUCHILLET, Dominique (Org.). Medicinas tradicionais e medicina ocidental na Amazônia. Belém: MPEG/CNPq/SCT/PR/CEJUP/UEP, 1991.

CANESQUI, Ana Maria. Notas sobre a produção acadêmica de antropologia e saúde na década de 1980. In: ALVES, Paulo Cesar; MINAYO, Maria Cecília de S. (Orgs.). Saúde e doença: um olhar antropológico. Rio de Janeiro: Editora FIOCRUZ, 1994. p. 13-32.

CARVALHO, Ana Cecília Bezerra. Plantas medicinais e fitoterápicos: regulamentação sanitária e proposta de modelo de monografia para espécies vegetais oficializadas no Brasil. Tese (Doutorado em Ciências da Saúde) - Universidade de Brasília, Brasília, 2011.

CONSELHO FEDERAL DE FARMÁCIA. Guia prático do farmacêutico magistral. Brasília: Conselho Federal de Farmácia, 2017.

D’ALMEIDA, Sabrina Soares. Guardiãs das folhas: mobilização identitária de raizeiras do cerrado e a autorregulação do ofício. Tese (Doutorado em Antropologia Social) - 
Universidade de São Paulo, São Paulo, 2018.

DECLARAÇÃO DE ALMA-ATA. Conferência Internacional Sobre Cuidados Primários de Saúde. Alma-Ata: URSS, 6-12 de set. 1978.

DIAS, Jaqueline Evangelista; LAUREANO, Lourdes Cardozo (Coords.). Farmacopeia popular do Cerrado. Goiás: Articulação Pacari (Associação Pacari), 2009.

DIAS, Jaqueline Evangelista; LAUREANO, Lourdes Cardozo (Orgs.). Protocolo comunitário biocultural das raizeiras do Cerrado: direito consuetudinário de praticar a medicina tradicional. Turmalina: Articulação Pacari, 2004.

EVANGELISTA, Jaqueline; LAUREANO, Lourdes. Community pharmacies and the promotion of local health care. Leisa Magazine, v. 23, n. 3, set. 2007.

EVANGELISTA, Jaqueline; LAUREANO, Lourdes. Medicina popular e biodiversidade no Cerrado. Revista Agriculturas, v. 4, n. 4, p. 6-10, dez. 2007.

FLEISCHER, Soraya. Parteiras, buchudas e aperreios: uma etnografia do atendimento obstétrico não oficial em Melgaço, Pará. Belém: Paka-Tatu; Ednisc, 2011.

IORIS, Edviges (Coord.). Plantas medicinais do Cerrado: perspectivas comunitárias para a saúde, o meio ambiente e o meio sustentável. Anais do Workshop Plantas Medicinais do Cerrado. Mineiros (GO): Fundação Integrada Municipal de Ensino Superior; Projeto Centro Comunitário de Plantas Medicinais, 1999.

MAUÉS, Raymundo Heraldo. Medicinas populares e "pajelança cabocla" na Amazônia. In: ALVES, Paulo César B.; MINAYO, Maria Cecília de Souza (Orgs.). Saúde e doença: um olhar antropológico. Rio de Janeiro: Fiocruz, 1994. p. 73-82.

MONTERO, Paula. (Org.). Deus na aldeia: missionários, índios e mediação cultural. São Paulo: Globo, 2006.

MONTERO, Paula. Da doença à desordem: a magia na umbanda. Rio de Janeiro: Graal, 1985.

OLIVEIRA, Elda Rizzo de. Doença, cura e benzedura: um estudo sobre o ofício da benzedeira em Campinas. v. I. Dissertação (Mestrado em Antropologia Social) - Universidade Estadual de Campinas, Campinas, 1983.

OLIVEIRA, Elda Rizzo de. O que é medicina popular. São Paulo: Brasiliense, 1985.

PESQUISA Popular de Plantas Medicinais. Rede de Intercâmbio de Tecnologias Alternativas, Articulação Pacari - Plantas Medicinais do Cerrado. Belo Horizonte: Rede de Intercâmbio, 2004.

SANTOS, Francimário Vito dos. O ofício das rezadeiras: um estudo antropológico sobre as práticas terapêuticas e a comunhão de crenças entre as rezadeiras de Cruzeta/ RN. Dissertação (Mestrado em Antropologia) - Universidade Federal do Rio Grande do Norte, Natal, 2007.

SEGATO, Cristiane; RIBEIRO, Aline. Você confia nas ervas medicinais? 29/08/2010. Disponível em: http://revistaepoca.globo.com/Revista/Epoca/0,,EMI166873-15257,00-VOCE+CONFIA+ NAS+ERVAS+MEDICINAIS.html. Acesso em: 04 mai. 2020.

TAMBIAH, Stanley Jeyaraja. Magic, science, religion, and the scope of rationality. Cambridge: Cambridge University Press, 1990.

TAMBIAH, Stanley Jeyaraja. Múltiplos ordenamentos de realidade: o debate iniciado por Lévy-Bruhl. Tradução de Daniel Belik e Stella Zagatto Paterniani. Cadernos de Campo, São Paulo, n. 22, p. 193-220, 2013.

TERRA DE DIREITOS. Conhecimento tradicional: Entrevista com Lourdes Laureano, co- 
Sabrina D'Almeida

ordenadora da Articulação Pacari. 17/12/2014. Disponível em: https://www.terradedireitos.org.br/noticias/noticias/conhecimento-tradicional-entrevista-com-lourdes-laureano-coordenadora-da-articulacao-pacari/16634. Acesso em: 24 abr. 2020.

TONIOL, Rodrigo. Do espírito na saúde: oferta e uso de terapias alternativas/complementares nos serviços de saúde pública no Brasil. Tese (Doutorado em Antropologia Social) - Universidade Federal do Rio Grande do Sul, Porto Alegre, 2015.

TONIOL, Rodrigo. Práticas integrativas e complementares: uma discussão inicial sobre a incorporação de terapias alternativas no SUS. Trabalho apresentado na $28^{\mathrm{a}}$ Reunião de Antropologia. São Paulo, 02-05 de julho de 2012. 